\title{
A simplified energy management system towards increased energy efficiency in SMEs
}

\author{
Adnan Hrustic ${ }^{1}$, Per Sommarin ${ }^{1, *}$, Patrik Thollander ${ }^{2}$, Mats Söderström² \\ ${ }^{1}$ Swerea SWECAST AB, Jönköping, Sweden \\ ${ }^{2}$ Department of Management and Engineering, Linköping University, Linköping, Sweden \\ *Corresponding author. Tel: +46 036301225, Fax: +46 036166866, E-mail: per.sommarin@swerea.se
}

\begin{abstract}
Swedish companies have since 2003 been able to get certified by an energy management system (EEMS) and companies that have been certified, can now show savings in energy use. The downside of today's EEMs is that too few small and medium-sized enterprises (SMEs) have chosen to certify such a system in the organization. To increase awareness and interest among SMEs, a simplified version of the EEMS would be desirable. This article presents a simplified EEMs for SMEs developed from the original European standard (SSEN 16 001). The article describes how the simple EEMS was developed and how the system was validated, i.e. how different companies responded to test-runs of the developed simplified EEMS. By testing the simplified EEMS in practice among various SMEs, different needs from the industry have been documented. The requests that were of greatest importance was how different incentives can be designed to increase the certification level, e.g. tax exemptions etc. The Swedish LTA for energy-intensive industries includes tax exemptions, as well as the certification of the European EEMS standard, and has shown to lead to large energy savings. An examples of a future energy policy could thus be a Long-Term Agreement (LTA)s program for SMEs including the simplified EEMS.
\end{abstract}

Keywords: Energy management, SME, Industrial energy efficiency, PFE

\section{Introduction}

Increased global warming is posing a major threat to global environment. The industry is a large emitter of carbon dioxide emissions, the major green house gas, and accounting for about 78 percent of the world's annual coal consumption, 41 percent of the world's electricity use, 35 percent of the world's natural gas consumption, and nine percent of global oil consumption [1]. Industrial energy efficiency is one of the most significant means of reducing the threat of increased global warming [2]. During the last decade, energy prices rose significantly for the Swedish industry. Between 2000 and 2006, electricity prices in Swedish industry almost doubled and oil prices rose by about 70 percent [3]. Even more price increases are to be expected, not least as a consequence of planned tax increases in the nation. The electricity price increase has partly been due to the liberalization of the European electricity markets. The liberalization caused the domestic markets to converge and Sweden has for a long time enjoyed one of the lowest electricity prices in Europe, see, e.g. [4]. Oil price increases may not create competitive disadvantages solely for Swedish industry. Electricity price increases on the contrary most likely will. This is particularly related to the Swedish industries and the fact that the historically low electricity prices have resulted in a higher use of electricity than for their European competitors in many Swedish industrial sectors, see [4] for a comparison in the European foundry industry.

Two main means exist of overcoming the threat of rising energy prices for the Swedish industry. One is to focus on managing the energy supply side with diversified portfolios etc. and, the other means is energy management focusing on a reducing energy end-use at the company. In regard to the latter, an EnErgy Management System (EEMS) may be a tool supporting companies in this important work. However, for most companies, not the least small- and medium-sized enterprises (SMEs), the certification of an EEMS is far too costly. The cost for an EEMS certification in Sweden is approximately 8000 EUR. The need for 
developing an EEMS for SMEs can thus not be understated. The aim of this study has been to develop an EEMS for SMEs. The conducted research has been inspired by the European standard for EEMS but is a stand-alone product with a graphical interface. The paper is outlined as follows. Initially, the background to the paper (introduction) is presented, followed by a presentation of energy efficiency in SMEs, and a presentation of the methodology. After that, the developed EEMS is presented, and finally, results and major conclusions are presented.

\section{Energy efficiency in SMEs}

Even though energy management is stated to be an important means for reducing industrial energy costs and reducing negative environmental impact [5-6], with some exceptions, e.g. [5-10], energy management in industry may be considered a scarcely researched subject. In regard to SMEs having limited resources to work with energy efficiency and energy management, a full-scale, in-house energy management program may not be justifiable [11]. For example, the cost of an energy management program, e.g. certification of an EEMS etc., may be in parity with the annual energy cost at an SME. A simplified EEMS for SMEs could thus be a means for increased energy management practices.

In Sweden, a few studies on barriers to energy efficiency among SMEs have been conducted [4,12-13]. Major barriers include: lack of time or other priorities/other priorities for capital investments, lack of access to capital/lack of budget funding, cost of production disruption/hassle/inconvenience, technical risk such as risk of production disruptions, difficulty/cost of obtaining information on the energy use of purchased equipment [9,22-23]. High-ranked barriers to energy efficiency among SMEs such as lack of time and other priorities, outlines the need for support, support which should not be too costly due to the barriers lack of access to capital, and moreover should involve information (difficulty/cost of obtaining information) [9,22-23]. A simplified EEMS developed for SMEs may overcome many of the barriers to energy efficiency and facilitate the adoption and governance of energy management in the sector.

\section{Methodology}

Swerea SWECAST conducts a research project named ENIG (Energy Efficiency In Group) together with Swerea IVF and FSEK (Association of Swedish Regional Energy Agencies). Project ENIG includes a number of research and development tasks to promote energy efficiency in Swedish industry [14].

A task in the project ENIG is "To develop a simplified EEMS for SMEs ", which means that a system promoting industry for energy efficiency will be developed based on the existing European standard for energy management systems, EN 16001. The new EEMS will serve as guidance for companies in their work with management systems. Most companies that have adopted energy management are outside the definition of SMEs. The reason for this is that many companies lack the resources to establish management systems, but also the lack of incentives that could increase the level of certification within the SMEs.

At a later stage, there are expectations that the simple EEMS in turn could help SMEs with the introduction of the real European standard, EN 16001, or the coming international standard ISO 50001 [15] . 
SIS Publishing Co. owns the copyright to SS-EN 16001 and because of legal reasons, an interconnection with the original standard had to be excluded. The application has been developed considering that it could be upgraded meaning that SMEs could get certified according to SS-EN 16 001. The management system is based on the PDCA-method (PlanDo-Check-Act-method). Figure 1 shows an illustration on the PDCA-method and how it leads to continuous improvement.

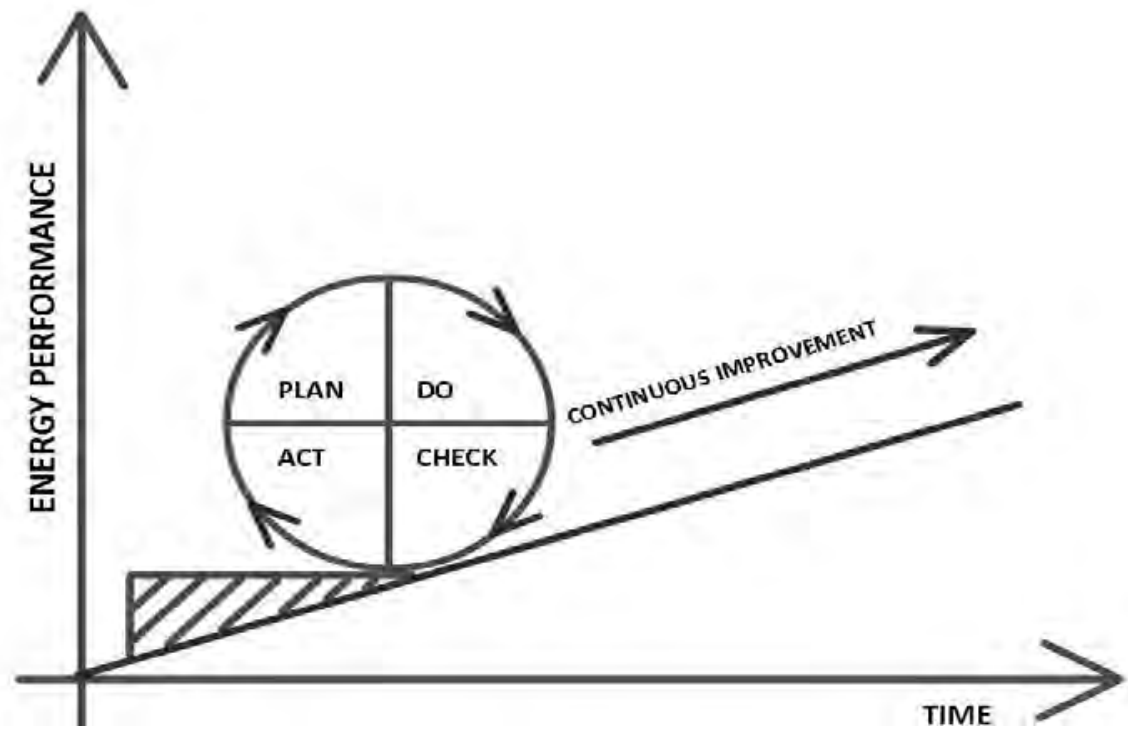

Figure 1: Continuous improvement with the PDCA-method. [16]

The simplified EEMS is built using lean production as a way of thinking when introducing energy use in EEMS [17] and its graphical interface is developed using Adobe Flash and Adobe Acrobat. It is developed as a presentation of the EEMS, and the SMEs should by working through the presentation; learn how to start working with EEMS. The simplified EEMS is more or less a self-learning system. To make the program more interesting and userfriendly, focus on how to build the interface resulted in the use of Adobe Acrobat. The EEMS program takes the user through the EEMS step by step by linking the slides with each other. The linking is made following the PDCA-method, see figure 2.

To improve the simplified EEMS even more, different companies in different sectors were visited and were asked to test-run the program. Interviews were held concerning how the SMEs would like to work with a management system and why they didn't certify in accordance with the original standard. During the test-run, the EEMS was demonstrated and a review on how it differed from the real standard was explained. The results were documented and from the testing results, changes were made in the EEMS. The testing of the simplified EEMS was divided into two phases, the first one with companies that have worked with EEMS for a while and have experience on how to organize their work with energy improvements. The second phase included SMEs, mainly without any experience with management systems. With results from the site visits and test runs, the EEMS could be developed even further and included a validation of the developed program, i.e. how compatible it was in practice for SMEs.

\section{Results - simple EEMS program}

SMEs can benefit from a simplified EEMS, because they usually have lack of resources and time to look for the best practices that are relevant to their sector [18]. Figure 2 shows how the system is built and how every part of the system is linked together. 


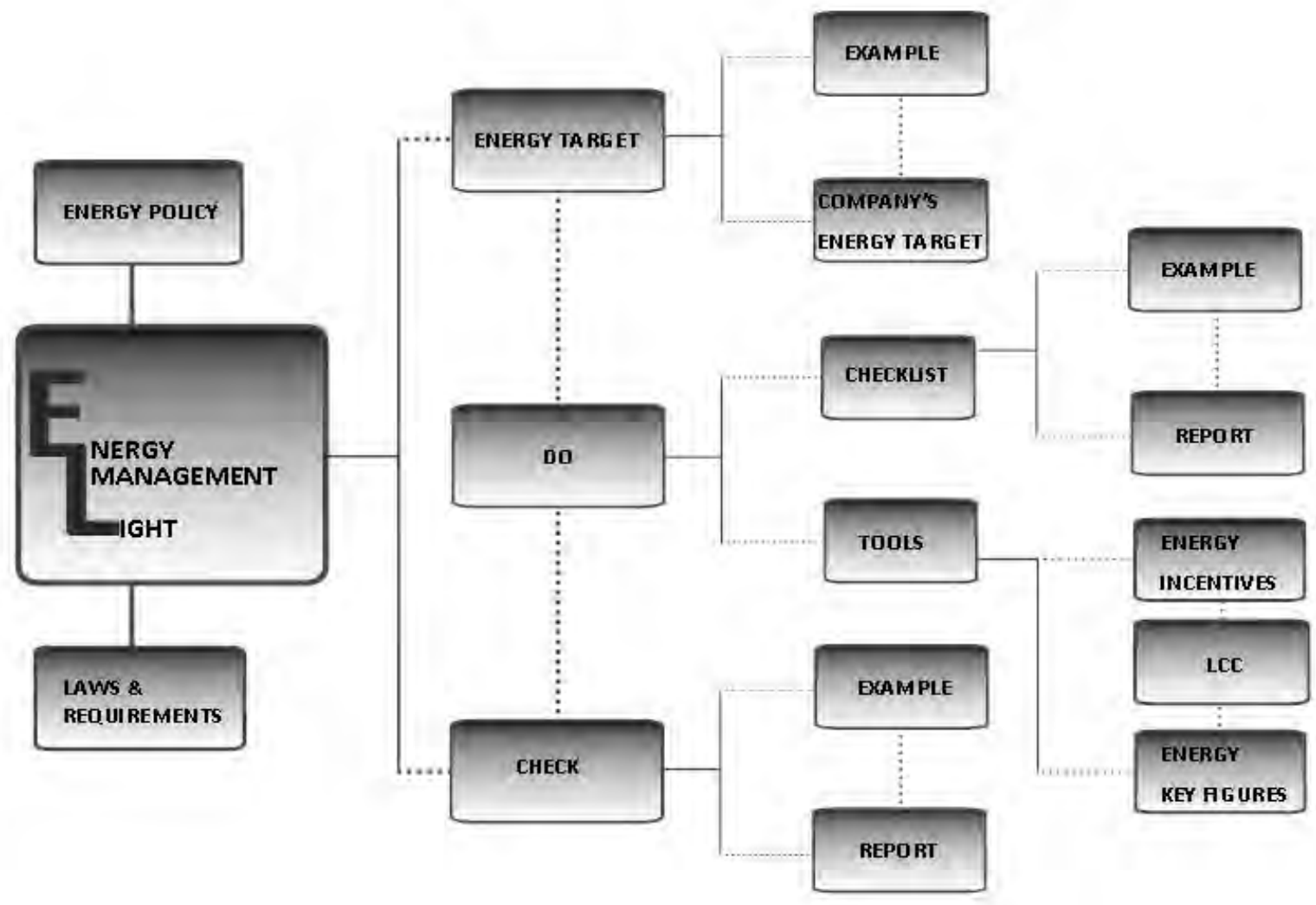

Figure 2: How the different parts from the simple EEMS are linked together.

To implement the simplified EEMS, companies should go through the management system in the following order:

$1^{\text {st }}$. Energy Policy: The company should define an energy policy. Some requirements for an energy policy are that, it should be simple, easy and possible to communicate to everyone in the company. The Energy Policy will be the document that is published and it shows how the company plans to work with energy efficiency. It is important to write an easily understandable to understand policy and it is desirable that all the staff from the company agrees on what is expressed in the policy.

$2^{\text {nd }}$. Laws and standards: Update the laws and requirements that could affect the company's work. Documenting a record of national, but also international laws and standards is a way to identify what rules the company should adjust its energy use for. The laws and requirements that concern the company will be documented and saved for future monitoring.

$3^{\text {rd }}$. Implementation: The implementation part of the EEMS consists of two parts, checklist and energy tools. Introducing a checklist could be used as guidance for companies in their energy use, see figure 3. By introducing different energy tools in the company, they will have more alternatives to improve the work with energy efficiency. The energy tools that the company could use in their energy work are energy incentives, LCC and key energy figures etc.

$4^{\text {th }}$. Follow up: In the follow-up, companies should review their results, through a review of the energy management practices conducted. The review should address the energy policy and work with energy efficiency at the company. In order to facilitate the revision an example 
paper was developed to show which parts that are the most important to review. A proper follow up of the management system should find different discrepancies that exist in the energy targets. By eliminating the discrepancies, companies could improve their level of energy efficiency.

\section{REPORT CHECKLIST}

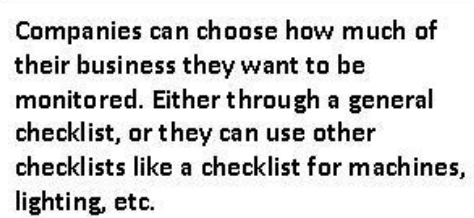

Figure 3: How EEMS presents the different checklists.

$5^{\text {th }}$. Continuous improvement: The companies should always work with continuous improvement of the simple EEMS, see figure 4.

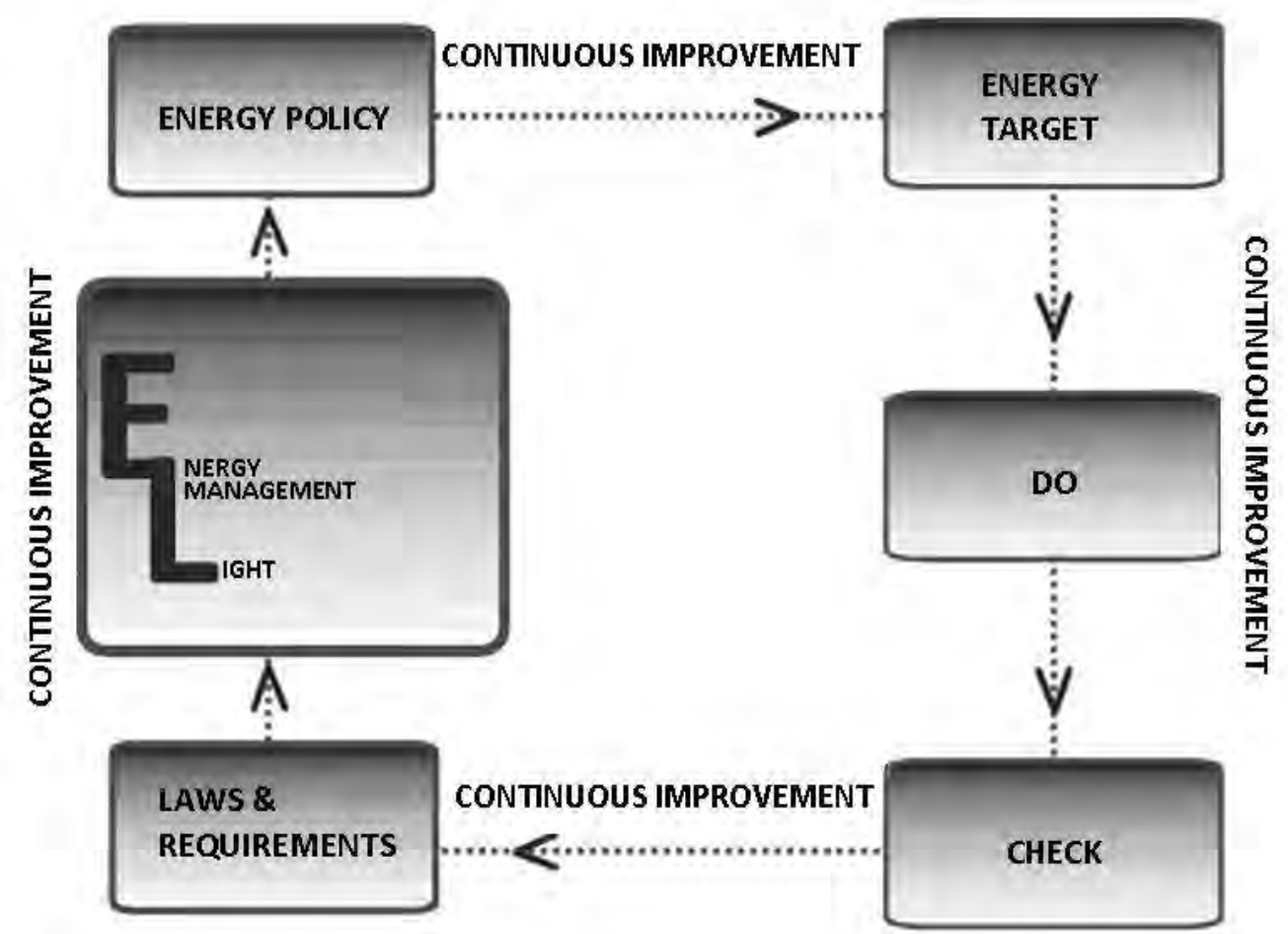

Figure 4: Continuous improvement of the simple EEMS. 
If the company wants to do an effective work with their management system they have to dare to act and improve. In order to improve the simplified EEMS, anomalies in the system could be reduced and the the energy efficiency could be increased.

\subsection{Validation of the developed EEMS program}

Test runs of the simple EEMS have contributed to a continuous improvement of the program on how they would like to use an energy management system.

In early development of the simple EEMS, people with a greater insight on how to work with management functions were visited. The people who attended the first testing may be seen as either energy experts at the Swedish Energy Agency or staff from large industries with a wellknown reputation from decades of successful energy management practices.

The improvements that were made during the test runs in the first phase were how the simplified EEMS could be more easily understood and user friendly. An idea from one of the industrial respondents was that if companies were trying to work according to the leanproduction philosophy, they would automatically understand how EEMS is supposed to work. By implementing a presentation on how lean production and EEMS are linked together a more user friendly approach could thus be achieved.

During the meeting with respondents from the Swedish Energy Agency, ideas resulted in adapting checklists in the simplified EEMS, arguing that a checklist is an easy way to do an energy audit of the energy use in a SME. The meeting with another industry respondent helped to develop an EEMS towards a more user-friendly interface. The respondent working full time with certified environmental and energy management systems could contribute with thoughts and ideas about how the workflow should be improved.

After the site visits and meetings with respondents at the Swedish Energy Agency, the EEMS was now ready to go into phase two, which was testing the EEMS among SMEs. Four companies were visited during the test phase.

Feedback from the test runs in phase two was solely positive. The test-runs gave a useful view on how the SMEs would like to work with an EEMS. All of the four companies thought that the simplified EEMS was easier to use, smoother, based on common sense and required less resources to implement than the original SS-EN 16001.

The Swedish LTA for energy-intensive industries includes tax exemptions, as well as the certification of the European EEMS standard (SS-EN 16 001), and has shown to lead to large energy savings (about 1.4 TWh electricity annually). A request from one of the company respondents test runs was to use the simplified EEMS in an LTA (Long-Term Agreements) specially tailored for SMEs in the future. The main reason why the company participating in the test-run did not participate in the current LTA was due to too high certification EEMS costs.

\section{Conclusion}

This work together with previous research by Thollander and Dotzauer (2010) [11], indicates that a simple and less costly version of an EEMS is desirable among SMEs. By developing an EEMS suited for smaller organizations, it could help companies to increase their level of knowledge on how to organize their business in regard to energy management, and thus enabling increasing levels of energy efficiency in the company. Increased understanding of 
energy management could contribute to more companies seeing the potential for energy efficiency and energy management.

Even if companies do not consider that they need an EEMS, a shorter training or insight into the simplified EEMS would help companies to realize the importance of organizing their energy management work. By trying to reduce inventories, increase productivity, improve quality, they can become more competitive and (energy) efficient in their business. Moreover, by increasing awareness on how production is managed, this may contribute to a reduction of energy use.

One incentive could be an LTA with tax exemption if companies used the simplified EEMS, like the Swedish PFE for energy-intensive industries.

PFE was found to show large energy savings among the participating companies and the project showed that companies succeed in saving energy through certification of an EEMS. However, PFE for SMEs should have greater demands for education and training in management systems and a required implementation of an energy audit. By informing companies how to use an EEMS, they could implement routines on how to use the data they receive through an energy audit.

According to the company-visits, the simplified EEMS program proved easy to use, none of the visited SMEs who made test-runs of the program thought it was inconceivable. However, more test-runs are needed to further shape the program into a final form. The estimation is that about 20 test runs would be needed to get an insight into how well the simplified EEMS performs among SMEs. Another interesting test-run, which was not performed, is to let a few companies use the simple EEMS for a longer period. This test run could be a good feedback on how well a simple EEMS actually works for a longer period and if the companies can achieve savings in their energy use.

A final conclusion is that a simplified EEMS can help companies to start implementing the measures that are deduced from an energy audit. An obstacle for energy audits to become useful is that they may end up in a "desk drawer", i.e. the company has not been able to use the new information. The main reason is that companies lack tools for how to deal with all of the new data obtained from an energy audit. By using a simplified EEMS, companies have now a tool that creates routines that measure and document their use of energy and their work to increase energy efficiency. Thus, companies can, through the developed program, achieve a support to spot inefficiencies in their energy use and realize that they can increase profits by reducing their energy use.

\section{References}

[1] IEA (International Energy Agency), 2007. Key world energy statistics 2007, Paris. Retrieved January 8, 2008, from: http://195.200.115.136/textbase/nppdf/free /2007/key_stats_2007.pdf

[2] IPCC, 2007. Contribution of Working Group III to the Fourth Assessment Report of the Intergovernmental Panel on Climate Change. Summary for Policymakers. Retrieved October 8, 2007, from: http://www.ipcc.ch/SPM0405 07.pdf

[3] Johansson, B., Modig, G., Nilsson, L.J., 2007. Policy instruments and industrial responses - experiences from Sweden. In: Proceedings of the 2007 ECEEE summer study “Saving energy - just do it”, Panel 7, 1413-1421.EEPO (2003) 
[4] Rohdin, P., Thollander, P., Solding, P., 2007. Barriers to and drivers for energy efficiency in the Swedish foundry industry. Energy Policy;35(1):672-77.

[5] Thollander, P., Ottosson, M., 2010. Energy Management practices in Swedish energyintensive industries, Journal of Cleaner Production 18(12):1125-1133.

[6] Worrell, E., Bernstein, L., Roy, J., Price L., and Harnisch, J., 2009. Industrial energy efficiency and climate change mitigation. Energy Efficiency 2:109-123.

[7] Christoffersen, L.B., Larsen, A., Togeby, M., 2006. Empirical analysis of energy management in Danish industry. Journal of Cleaner Production;14(5):516-26.

[8] McKane, A., Williams, R., Perry, W., T, L., 2007. Setting the Standard for Industrial Energy Efficiency Retrieved, December 9, 2009, from: http://industrialenergy.lbl.gov/node/399

[9] Caffal, C., 1996. Energy management in industry. Centre for the Analysis and Dissemination of Demonstrated Energy Technologies (CADDET). Analysis Series 17. Sittard, The Netherlands.

[10]Bunse, K., Vodicka, M., Schönsleben, P., Brülhart, M., Ernst, F.O., 2011. Integrating energy efficiency performance in production management - gap analysis between industrial needs and scientific literature. Journal of Cleaner Production, In Press.

[11] Thollander, P., Dotzauer, E., 2010. An energy efficiency program for Swedish industrial small- and medium-sized enterprises. Journal of Cleaner Production 18(13):1339-1346.

[12] Thollander, P., Rohdin, P., Danestig, M., 2007. Energy policies for increased industrial energy efficiency: Evaluation of a local energy programme for manufacturing SMEs. Energy Policy;35(11):5774-83.

[13]Rohdin, P., Thollander, P., 2006. Barriers to and Driving Forces for Energy Efficiency in the Non-energy Intensive Manufacturing Industry in Sweden. Energy;31(12):1836-44.

[14] Swerea, SWECAST. Project ENIG. http://www.swerea.se/enig/. Taken 2011-02-30

[15]SIS Förlag, SS-EN 16001, Energy management systems - Requirements with guidance for use, European Committee for Standardization published 2009-07-01

[16] Arveson, P. Lacknerl, P \& Holanek, N. Step by step guidance for implementation of energy management, Benchmarking and Energy Management Schemes in SMEs. Rapport, published 2007-01-01

[17] Johansson, P-E., 2011. Lean production. Dynamate, Sweden.

[18] Shipley, A.M., Elliot, R.E., 2001 Energy Efficiency Programs for Small and Medium Sized industry. In: Proceedings of the 2001 ACEEE summer study on energy efficiency in industry, vol. 1, 183-196. 